\title{
POPULATION STUDY ARTICLE Death review of children receiving medical care at home
}

\author{
Jun Natsume $\mathbb{D}^{1,2,3}$, Atsushi Numaguchi ${ }^{3,4}$, Atsuko Ohno ${ }^{5}$, Mihoko Mizuno ${ }^{3,6}$, Yoshiyuki Takahashi ${ }^{1}$, Akihisa Okumura ${ }^{7}$, \\ Tetsushi Yoshikawa ${ }^{8}$, Shinji Saitoh ${ }^{9}$, Kiyokuni Miura ${ }^{3,10}$ and Masaharu Noda ${ }^{3}$
}

BACKGROUND: Children receiving home medical care need special attention to prevent unexpected death. The aim of this study was to clarify the factors contributing to death in children receiving home medical care from the child death review database. METHODS: Children receiving home medical care were enrolled from the child death review database from 2014 to 2016 in Aichi prefecture, Japan, with a population of one million children. Types of medical care and factors contributing to death were examined.

RESULTS: Of the 631 children who died, 40 children (6\%) were receiving home medical care (21: tracheostomy; 19: ventilator; 26 : suctioning of naso-oral secretions; 19: oxygen inhalation; 32 : tube feeding; 6 : urethral catheterization; and 1: peritoneal dialysis). The death rate was 50 times that in the general population of children. Ten children had contributory factors that seemed to be preventable. In four children, the families could not replace the tracheostomy tubes during an accident. In three, oxygen saturation or ventilator alarms were not set appropriately. In two, an oxygen cylinder became empty. One child fell down from a seat in a car. CONCLUSIONS: Improvement of devices and correct guidance to caregivers may reduce the death rate in children receiving home medical care.

Pediatric Research (2022) 91:1286-1289; https://doi.org/10.1038/s41390-021-01606-3

\section{IMPACT:}

- Children receiving home medical care, such as tracheostomy care, mechanical ventilation, or tube feeding, need special attention to prevent unexpected death.

- In this population-based child death review, $6 \%$ of children received home medical care, and it was estimated that 1 of 100 children receiving home medical care died per year.

- One-quarter of the deaths could be preventable by caregiver education or development of devices.

\section{INTRODUCTION}

Child mortality has decreased, particularly in developed countries. ${ }^{1}$ At the same time, the prevalence of children with severe disability has increased along with the improved survival rate of children treated in neonatal intensive care units, emergency departments, and pediatric intensive care units. ${ }^{2,3}$ Many children with severe disabilities require home medical care, including management of a tracheostomy, mechanical ventilation, and tube feeding. The prevalence of home medical care is increasing in Japan. Based on the survey of the Ministry of Health, Labour and Welfare in Japan, the number of children $<20$ years of age with home medical care increased to 20,000 in 2018 from 10,000 in 2005. In Aichi prefecture, which has 7.5 million residents, $>1000$ children were receiving home medical care according to the survey of the Aichi prefectural government in 2019. On the other hand, there are no reports on the mortality of children receiving home medical care in Japan. Children receiving home medical care need special attention in daily life to prevent accidents and unexpected death. Reducing factors leading to the death of children receiving home medical care is an important issue. ${ }^{4}$

There has been increased interest in child death review (CDR) to shed light on the causes of unexpected death in children. The purpose of CDR is to identify the data related to the cause of child death and to provide recommendations to prevent future deaths. ${ }^{5}$ Although child death registration processes and review systems are established in some countries, there are concerns about their accuracy and recommendation strategies. ${ }^{5}$ Moreover, there are no reports of the death of children receiving home medical care from population-based CDR database.

In Japan, CDR systems are being developed. Although CDR has been studied as a model project of the Ministry of Health, Labour and Welfare of Japan, CDR is not officially performed by the government. In Aichi prefecture, which has 7.5 million residents, CDR was performed as a retrospective, multicenter study of medical universities and hospitals from 2014 to 2016. The aims of the present study were to clarify the incidence of death in children

\footnotetext{
${ }^{1}$ Department of Pediatrics, Nagoya University Graduate School of Medicine, Nagoya, Japan; ${ }^{2}$ Department of Developmental Disability Medicine, Nagoya University Graduate

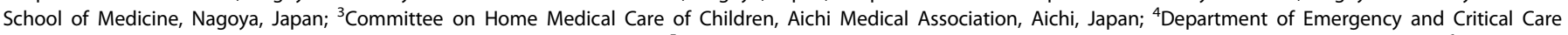

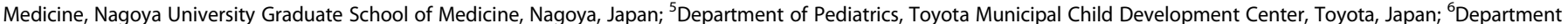

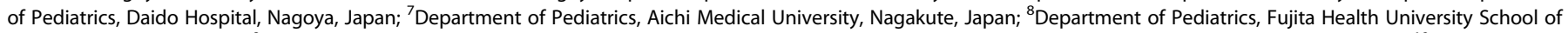

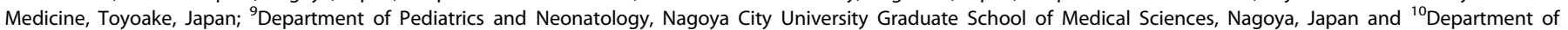
Pediatric Neurology, Aichi Developmental Disability Center, Kasugai, Japan

Correspondence: Jun Natsume (junnatsu@med.nagoya-u.ac.jp)
}

Received: 30 December 2020 Revised: 14 May 2021 Accepted: 20 May 2021

Published online: 8 July 2021 
receiving home medical care and to identify factors contributing to preventable death from the CDR database. We expect that this will provide important information for the prevention of future deaths in children receiving home medical care.

\section{METHODS}

This study was approved by the institutional review board of Nagoya University Graduate School of Medicine. Because of the retrospective nature of the study and anonymization, informed consents from caregivers of the children who died were not obtained.

Children $<15$ years of age at the time of death in Aichi prefecture in Japan from 2014 to 2016 were retrospectively identified from the record of hospitals that had Departments of Pediatrics for the purpose of CDR. Aichi Prefecture had 7.5 million residents and 1.0 million children $<15$ years of age in 2014. In the creation of the CDR database, all 121 hospitals that had pediatric beds in Aichi prefecture were asked if there were children who had died during the study period; all 121 hospitals responded. Survey sheets were then provided to the 40 hospitals that had children who had died during the study period to extract the clinical information. It was confirmed that there were no children who died in hospitals without pediatric beds during the study period from the government data. The anonymized survey sheets were completed by pediatricians of the hospitals in which the children died. The survey sheets included age, sex, direct cause of death, situation at death, pre-existing disease, patient and family background, past history, and possibility of abuse. The cause of death was identified from medical charts as well as medical certificate of cause of death. At the CDR, the completed sheets were reviewed by clinicians (pediatricians, emergency physicians, psychiatrists, and surgeons), forensic pathologists, government staff (child consultation center, healthcare center, and others), and law enforcement staff. The adequacy of the descriptions in the sheets and preventive measures were discussed in the meeting.

The electronic database was managed by the principal investigator of the CDR, A.N. Four members (J.N., A.Ohno, M.M., and A.N.) of the present study assessed all survey sheets and the results of the discussions at the CDR. All information for the children on home medical care was extracted from the CDR database. The medical care at home included tracheostomy care, ventilator management, suctioning of nasal and oral secretions, oxygen inhalation, tube feeding, urethral catheterization, and peritoneal dialysis. Children who died out of a hospital or within 30 days after emergency admission because of respiratory failure or cardiopulmonary arrest were included.

The situation of home medical care was also investigated by asking the physicians in the hospitals in which the children died. Underlying disorders, motor function of the children, medical devices at home, medical and domestic situations before death, and the factors contributing to death were investigated. Four members (J.N., A.Ohno, M.M., and A.N.) determined the factors contributing to death and the possibility of preventing each death in the meeting. Particular attention was paid to abnormalities of medical devices and attitudes of the caregivers, as well as the registered cause of death, in CDR. When important information was missing, the physicians who attended the patients were contacted to obtain the missing information. From this clinical and environmental information, four members of the present study (J.N., A.Ohno, M.M., and A.N.) determined the possibility of preventing each death. When opinions regarding the possibility of prevention differed, a consensus was reached by discussion.

Regarding the definition of unexpected and preventable death in the CDR in Aichi prefecture, unexpected death was defined with reference to the criteria of Blair et al., although the criteria were for infants. ${ }^{6}$ Preventable death was defined with reference to the concepts of avoidable death of Pearson et al., ${ }^{7}$ which were as

\begin{tabular}{|c|c|}
\hline & $\begin{array}{l}\text { Number of } \\
\text { patients }\end{array}$ \\
\hline \multicolumn{2}{|l|}{ Underlying disorder } \\
\hline $\begin{array}{l}\text { Chromosomal abnormality (trisomy } 18, \text { trisomy } 13, \\
\text { trisomy } 21,4 p \text { monosomy, } 18 p \text { tetrasomy) }\end{array}$ & 13 \\
\hline $\begin{array}{l}\text { Congenital heart anomaly ( } 10 \text { of } 15 \text { had a } \\
\text { chromosomal abnormality) }\end{array}$ & 15 \\
\hline $\begin{array}{l}\text { Noncardiac congenital anomaly } \\
\text { (holoprosencephaly, lissencephaly, schizencephaly, } \\
\text { hydrocephalus, Chiari malformation, meningocele, } \\
\text { achondroplasia, thanatophoric dysplasia, Pierre } \\
\text { Robin syndrome, Treacher-Collins syndrome, cleft } \\
\text { palate, tracheomalacia, thoracic hypoplasia, } \\
\text { esophageal atresia, gastro-esophageal reflux, } \\
\text { omphalocele, hypoplastic kidney, } \\
\text { lymphangiomatosis) }\end{array}$ & 19 \\
\hline Perinatal or acquired brain injury & 7 \\
\hline Neuromuscular disorder & 1 \\
\hline Developmental epileptic encephalopathy & 1 \\
\hline $\begin{array}{l}\text { Developmental delay and epilepsy of unknown } \\
\text { etiology }\end{array}$ & 1 \\
\hline \multicolumn{2}{|l|}{ Types of home medical care } \\
\hline Tracheostomy & 21 \\
\hline Mechanical ventilation & 19 \\
\hline Suctioning of nasal and oral secretions & 26 \\
\hline Oxygen inhalation (continuous 13, occasional 6) & 19 \\
\hline $\begin{array}{l}\text { Tube feeding (gastrostomy or enterostomy } 12, \text { nasal } \\
\text { or oral tube } 20 \text { ) }\end{array}$ & 32 \\
\hline Urethral catheterization & 6 \\
\hline Peritoneal dialysis & 1 \\
\hline \multicolumn{2}{|l|}{ Motor function } \\
\hline Unable to sit & 36 \\
\hline Sitting without support & 1 \\
\hline Standing without support & 2 \\
\hline Unknown & 1 \\
\hline
\end{tabular}

follows: $(A)$ where there were identifiable failures in the child's direct care by any agency, including parents, with direct responsibility for the child; $(B)$ where there were latent, organizational, or other indirect failure(s) within one or more agency, including parents, with direct or indirect responsibility for the child; and (C) where there was a failure of design, dilapidation of barriers, or inadequate maintenance by agencies with responsibility for public safety.

\section{RESULTS}

The CDR database consisted of 631 children $<15$ years of age who died from 2014 to 2016 in Aichi prefecture (Supplementary Table). The number of children covered $91 \%$ of all deaths of children reported in the government statistics (692 children). From the clinical information of the database, 40 children who had received medical care at home were enrolled. The median age at death was 2 years (range 4 months-14 years). The clinical characteristics, including underlying disorders, types of home medical care, and motor function, of the 40 children are shown in Table 1 . As regards the hospitals the children were transferred to at death, 28 children had regularly visited the hospital, eight had occasionally visited it, and four had not visited it. An autopsy was performed in only five children. 
Based on the review of clinical and environmental information, accidents and inappropriate use of medical devices were considered contributory factors that seemed to be preventable in ten children. In four children, tracheostomy tubes were obstructed by secretions or accidentally removed, and family members could not replace the tube correctly. In three patients, the oxygen saturation alarm was turned off, or the ventilator alarm was set to a very low tidal volume by the family because of frequently triggered alarms. In two patients, an oxygen cylinder became empty in a car or at home. One patient fell down from a seat in a car while a family member was driving. In the other 30 patients, the death was not considered preventable because the patients died due to progression of their underlying disorders, severe infectious diseases, or sudden worsening of their cardiorespiratory status.

\section{DISCUSSION}

In the CDR database of 646 children, 40 children (6\%) were receiving medical care by caregivers at home. More than half of the children were receiving respiratory care, including tracheostomy care, management of mechanical ventilators, or suctioning of nasal and oral secretions. In $25 \%$ of the children who died during home medical care, the death was possibly preventable by improvement of devices or provision of correct guidance to the caregivers.

A high possibility of death in children with severe disability receiving home medical care has been reported. ${ }^{8,9}$ A systematic review of nine studies showed that the strongest prognostic factors for the likelihood of death related to impaired mobility were lack of sitting ability at 24 months of age. ${ }^{8}$ It has also been reported that children who were dependent on long-term ventilation or tracheostomy had a high risk of death in the community setting. ${ }^{9}$ In the present study spanning 3 years in a population of one million children, 40 children died in the setting of home medical care. In the survey by the Aichi prefectural government in 2019, 1247 children $<15$ years of age were receiving home medical care. From the results of the present study and the government survey, it is roughly estimated that 1 of 100 children with home medical care died per year (40/1247 children/3 years). In the statistics of Aichi prefecture, the death rate of all children was 2 of 10,000 children per year in the period 2014-2016 (https://www.pref.aichi.jp/soshiki/iryo-keikaku/ h26eiseinenpou.html, h27eiseinenpou.html, and h28eiseinenpou. $\mathrm{html}$ ). The rate of death in children receiving home medical care was estimated to be 50 times that in the general population of children, although the survey period was not the same. The estimated rate of death in the present study is an important piece of information for considering policies and specific actions for the home medical care of children.

One of the most important purposes of CDR is to provide recommendations for preventing future deaths. ${ }^{10}$ It has been reported that half of the deaths in children on home mechanical ventilation with a tracheostomy were not related to the progression of underlying conditions and unexpected. ${ }^{11}$ In the present study, the death of ten children $(25 \%)$ receiving home medical care was considered possibly preventable. The most common factors were obstruction or accidental removal of tracheostomy tubes. In the previous study involving questionnaires given to caregivers, many caregivers answered that they trained with a tracheostomy and feeding tube before the child's discharge from the hospital, but they lacked knowledge of new situations and symptoms at home with medical technology. ${ }^{12}$ Whereas training of caregivers for routine replacement of tracheostomy tubes is performed repeatedly before discharge from hospitals and during home care, it may be difficult for caregivers alone to manage emergency conditions, such as urgent replacement of the tracheostomy tube. Better instruction and education in emergency response training of caregivers is needed. Another important factor is a monitoring alarm. Some of the caregivers may not fully understand the importance of the monitor alarms and are also tired of frequent alarms. Appropriate setting of alarms should be checked by home-visit nurses, and education of all family members should also be performed. Boroughs et al. identified three factors contributing to preventable deaths in ventilator-dependent children at home: (1) inadequate training (lack of familiarity with tracheostomy changes, ventilator alarms, and circuit troubleshooting); (2) improper response (failure to recognize an obstructed or dislodged tracheostomy tube, medical device failure); and (3) lack of vigilance (asleep, alarm fatigue). ${ }^{4}$ The present study confirmed the first two factors contributing to preventable deaths in children receiving home medical care. Although a guideline for pediatric chronic home invasive ventilation was released in 2016 in the United States, there is a lack of validated clinical guidelines, mainly because of the heterogeneity of ventilator servicing, the costs, and healthcare systems among countries. ${ }^{9,13}$ Nationwide guidelines matching the medical circumstances in each country should be created for the standardization of home mechanical ventilation and monitoring, as well as instruction and checklists for emergency response training of caregivers.

In the present study, two children died because of lack of oxygen in cylinders, and one died by falling from a car seat. These factors should be prevented by improvement of devices. Usual oxygen cylinders have pressure meters to show the remaining amount of oxygen, but it may be difficult for caregivers to know how long they can use the oxygen based on the pressure meters. More sophisticated alarm systems should become widely available. The instruments and methods for the safe fixation of children with a tracheostomy and a ventilator in cars have also not yet been standardized. The development and distribution of new devices for the safety of children receiving home medical care should be encouraged.

The present study has several limitations. First, only $91 \%$ of child deaths were captured in the CDR database; the lack of information for $9 \%$ of children is a limitation of the study. This CDR is hospitalbased and not performed by the government. The children for whom information could not be obtained were presumed to be ones who were not transferred to a hospital when they died, neonates who died just after birth at maternity clinics, and children who lived in Aichi prefecture but died outside of Aichi prefecture. For the precise CDR of all children who died, a systematic approach in cooperation with governments is needed. Second, the number of autopsies was very low. It is presumed that the medical staff may hesitate to suggest an autopsy to the family of children with a longterm illness, whereas an autopsy is important for the determination of the causes of death and related factors. We do not have a systematic coronial system in Japan. Postmortem autopsy is conducted by forensic doctors, by the request from a law enforcement mainly based on the criminality, not from a medical point of view by clinicians. It may be another reason of small number of autopsies. Third, because of the nature of a retrospective analysis of survey sheets, the details of the situation of death were difficult to obtain. An additional survey was performed to gather the details, especially about the condition of home medical care and children's motor function, to complement the clinical information. Prospective CDR should form the foundation for learning from child deaths going forward. Even with these limitations, the results of the present study give important information regarding children receiving home medical care.

In conclusion, $6 \%$ of children in the CDR database were receiving home medical care. Forty children receiving home medical care died, and ten of these children had potentially preventable contributory factors. The present results have implications for the training of and support for families providing home medical care to children with chronic illnesses. We should pay attention to these preventable factors that lead to cardiorespiratory arrest. CDR is useful to improve the safety of children receiving home medical care. 


\section{ACKNOWLEDGEMENTS}

This study was supported in part by Research Grant (19-DA1-002) from the Ministry of Health, Labor and Welfare in Japan. This study was supported by the Aichi Medical Association and the Aichi Pediatric Clinical Study Group. We wish to thank all the staff who contributed to the creation of the CDR database in Aichi prefecture. The funder/ sponsor did not participate in the work.

\section{AUTHOR CONTRIBUTIONS}

J.N. conceptualized and designed the study, collected the data, carried out the initial analyses, drafted the initial manuscript, and reviewed and revised the manuscript. A.N., A.Ohno, and M.M. designed the data collection instruments, collected the data, carried out the initial analyses, and reviewed and revised the manuscript. Y.T., A.Okumura, T.Y., S.S., K.M., and M.N. conceptualized and designed the study, coordinated and supervised data collection, and critically reviewed the manuscript for important intellectual content. All authors approved the final manuscript as submitted and agree to be accountable for all aspects of the work.

\section{ADDITIONAL INFORMATION}

Supplementary information The online version contains supplementary material available at https://doi.org/10.1038/s41390-021-01606-3.

Competing interests: J.N. is affiliated with the endowed department from Aichi prefectural government (Department of Developmental Disability Medicine). The other authors declare no competing interests.

Consent statement: Because of the nature of the retrospective study of the child death review database, informed consent from the families was not required.

Publisher's note Springer Nature remains neutral with regard to jurisdictional claims in published maps and institutional affiliations.

\section{REFERENCES}

1. Kassebaum, N. et al. Child and adolescent health from 1990 to 2015: Findings from the global burden of diseases, injuries, and risk factors 2015 study. JAMA Pediatr. 171, 573-592 (2017).

2. Cohen, E. et al. Children with medical complexity: an emerging population for clinical and research initiatives. Pediatrics 127, 529-538 (2011).

3. Gulla, K. M., Sahoo, T. \& Sachdev, A. Technology-dependent children. Int. J. Pediatr. Adolesc. Med. 7, 64-69 (2020).

4. Boroughs, D. \& Dougherty, J. A. Decreasing accidental mortality of ventilatordependent children at home: a call to action. Home Healthc. Nurse 30, 103-111 (2012).

5. Fraser, J., Sidebotham, P., Frederick, J., Covington, T. \& Mitchell, E. A. Learning from child death review in the USA, England, Australia, and New Zealand. Lancet 384, 894-903 (2014).

6. Blair, P. S., Byard, R. W. \& Fleming, P. J. Sudden unexpected death in infancy (SUDI): suggested classification and applications to facilitate research activity. Forensic Sci. Med. Pathol. 8, 312-315 (2012).

7. Pearson, G. A., Ward-Platt, M., Harnden, A. \& Kelly, D. Why children die: avoidable factors associated with child deaths. Arch. Dis. Child. 96, 927-931 (2011).

8. Nissen, S. et al. Impaired mobility associated with an increased likelihood of death in children: a systematic review. J. Child Health Care 22, 147-158 (2018).

9. Sterni, L. M. et al. An Official American Thoracic Society Clinical Practice Guideline: pediatric chronic home invasive ventilation. Am. J. Respir. Crit. Care Med. 193, e16-e35 (2016).

10. Quinton, R. A. Child death review: past, present, and future. Acad. Forensic Pathol. 7, 527-535 (2017).

11. Edwards, J. D., Kun, S. S. \& Keens, T. G. Outcomes and causes of death in children on home mechanical ventilation via tracheostomy: an institutional and literature review. J. Pediatr. 157, 955-959.e952 (2010).

12. Spratling, R. \& Lee, J. Caregivers experiences in symptom management for their children who require medical technology at home. J. Spec. Pediatr. Nurs. 25, e12275 (2020).

13. Khirani, S. et al. Follow-up and monitoring of children needing long term home ventilation. Front. Pediatr. 8, 330 (2020). 